\title{
Prevalence and Predictive Factors of Sexual Dysfunction in Iranian Women: Univariate and Multivariate Logistic Regression Analyses
}

\author{
Ashraf Direkvand-Moghadam', Zainab Suhrabi' ${ }^{2}$, Malihe Akbari' ${ }^{2}$ Azadeh Direkvand-Moghadam ${ }^{3, *}$ \\ ${ }^{1}$ Psychosocial Injuries Research Center, Faculty of Nursing and Midwifery, Ilam University of Medical Sciences, Ilam, Iran \\ ${ }^{2}$ Faculty of Nursing and Midwifery, Ilam University of Medical Sciences, Ilam, Iran \\ ${ }^{3}$ Student Research Committee, Ilam University of Medical Sciences, Ilam, Iran
}

\begin{abstract}
Background: Female sexual dysfunction, which can occur during any stage of a normal sexual activity, is a serious condition for individuals and couples. The present study aimed to determine the prevalence and predictive factors of female sexual dysfunction in women referred to health centers in Ilam, the Western Iran, in 2014.

Methods: In the present cross-sectional study, 444 women who attended health centers in Ilam were enrolled from May to September 2014. Participants were selected according to the simple random sampling method. Univariate and multivariate logistic regression analyses were used to predict the risk factors of female sexual dysfunction. Differences with an alpha error of 0.05 were regarded as statistically significant.

Results: Overall, $75.9 \%$ of the study population exhibited sexual dysfunction. Univariate logistic regression analysis demonstrated that there was a significant association between female sexual dysfunction and age, menarche age, gravidity, parity, and education $(\mathrm{P}<0.05)$. Multivariate logistic regression analysis indicated that, menarche age (odds ratio, 1.26), education level (odds ratio, 1.71), and gravida (odds ratio, 1.59) were independent predictive variables for female sexual dysfunction.

Conclusion: The majority of Iranian women suffer from sexual dysfunction. A lack of awareness of Iranian women's sexual pleasure and formal training on sexual function and its influencing factors, such as menarche age, gravida, and level of education, may lead to a high prevalence of female sexual dysfunction.
\end{abstract}

Keywords: Female Sexual Dysfunction; Prevalence of Sexual Disorders; Risk Factors for Sex Disorders

Received: March 4, 2016, Revised: April 25, 2016, Accepted: April 25, 2016

*Corresponding Author: Azadeh Direkvand-Moghadam Tel: +98-843-2240404, Fax: +98-843-2240404, E-mail: ashraf_dyrekvand@yahoo.com

'This study is associated with llam University of Medical Sciences, llam, Iran. 


\section{INTRODUCTION}

The recognition of women's health, and the elimination of confounding factors that affect their health, is of interest to medical science. ${ }^{1,2)}$ Sexual function is an important issue in human public health. ${ }^{3)}$ Sexuality is one of the main factors that affect an individual and his/her social life. ${ }^{4)}$ Sexual dysfunction is defined as a difficulty during any stage of normal sexual activity experienced by an individual or couple for a minimum of 6 months. This disorder may affect physical pleasure, desire, preference, arousal, or orgasm. ${ }^{5)}$ Approximately $40 \%$ of all women experience sexual dysfunction. ${ }^{6}$ )

Sexual dysfunction obviously affects an individual's quality of life, ${ }^{4)}$ including aspects such as marriage satisfaction and social performance. ${ }^{7)}$ Therefore, sexual satisfaction is considered to be one of the most important predictors of marriage satisfaction in couples. ${ }^{8)}$

Although some social psychological theories, such as the self-perception, the over justification, and the insufficient justification hypotheses, have considered female sexual dysfunction, there are other risk factors for sexual dysfunction, including the consumption of alcohol, nicotine, and drugs such as antihypertensive, antihistamines, and psychotherapeutics. ${ }^{910)}$ Psychological factors, such as depression, sexual fear or guilt, past sexual trauma, and sexual disorders, ${ }^{10-12)}$ also affect sexual function. Another study demonstrated the aging is associated with sexual function in women. ${ }^{13)}$

Infertility is also one of the factors affecting female sexual function. ${ }^{14)}$ A woman's childbearing role is particularly important in Islamic countries; therefore, sexual dysfunction is more common among Muslim infertile women. ${ }^{10,15)}$ A previous study reported that infertile women experience lower marital satisfaction and sexual desire than fertile women. ${ }^{15)}$ Our previous study demonstrated that all dimensions of female sexual function were reduced in infertile women, when compared with fertile women. ${ }^{10}$

Sexual disorders met with uncertainty in Iran and various others countries. However, sexual dysfunction is prevalent, regardless of whether or not it is not expressed.

As a serious and poorly understood complication of a woman's reproductive age, it is necessary to recognize the epidemiological and clinical risk factors of sexual dysfunction to recognize this dysfunction before it threatens to impact the quality of a couple's life. Therefore, the present study was conducted to determine the prevalence and predictive factors of female sexual dysfunction in women referred to the public and private health centers in Ilam, the Western Iran, in 2014.

\section{METHODS}

\section{Study Subjects}

The present cross-sectional study evaluated female sexual dysfunction. The study population consisted of married women who were admitted during the study period for mother or child's health services in public and private health centers in Ilam, the Western Iran, from May to September 2014.

Sampling was conducted in multiple stages. In the first stage, the city was divided into six clusters. Subsequently, a public and a private clinic were randomly selected from each cluster. Overall, six public and six private health centers were selected from different regions of Ilam. In Iran, public health centers only attend to customers in the morning, whereas private health centers only serve customers in the afternoon. However, each week the collaborator midwife randomly attended a public health center each morning and private health centers each evening during the six days from Saturday to Thursday. Sampling was performed by a trained midwife. In order to gain access to all women that attended, the midwife was stationed at the customer reception. Eligible and willing participants were led to the rooms intended for study, and the required information was collected. In each center, consecutive sampling of eligible participants continued until the sample size was attained. Previous studies have reported the prevalence of female sexual dysfunction in women as $40 \%{ }^{16)}$ Considering $\mathrm{P}=0.4, \mathrm{~d}=0.05, \alpha=5 \%$, and $1-\beta=80 \%$ (expected power), a required sample size of 369 women was calculated. Approximately $20 \%$ of eligible women submitted incomplete questionnaires; therefore, the sample population included 444 eligible women.

Data were collected by a trained research midwife. Inclusion criteria stated that all the women were married, aged 15-55 years old and willing to participate in the present study. All women were asked to recall confounding factors associated with sexual function, such as debate and controversy over the last months, stress events in the past three months, physical and psychosocial disorders, and consumption of alcohol or nicotine. Repeat clients were excluded (Figure 1). The study was approved by the Institutional Committee of Ethical Practice of our institution (no. 909015). The aim of the study was outlined for all participants. All participants completed the informed consent form. To enhance confidentiality, all questionnaires were completed anonymously and only required information was collected.

Study data were collected demographically and according to the Fe-

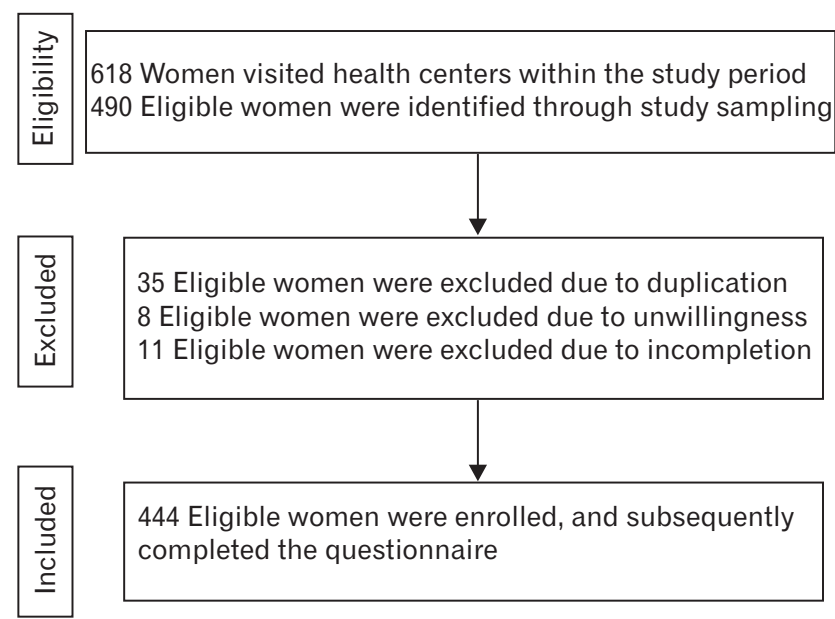

Figure 1. Schematic of the sampling procedures used. 
male Sexual Function Index (FSFI) scale by a trained research midwife. The demographic questionnaire contained variables such as age, occupation, and education of the husband and wife, monthly income, age at marriage, menarche age, gravity, and parity. However, the FSFI questionnaire included 19 items that were divided into six domains: desire, arousal, lubrication, orgasm, satisfaction, and pain. Each domain contained 2-4 questions that were scored based on the Likert scale. The validity and reliability of the FSFI questionnaire has been confirmed in various countries ${ }^{17-19)}$ and in Iranian women..$^{20,21)}$

The total score for each woman was calculated based on the score obtained from the 19-item questionnaire, ranging from 2 to 36 . A cutoff point of 28 was determined. Therefore, all women who achieved a total score of $>28$ were considered to have normal female sexual function, whereas all women who achieved a total score of $<28$ were considered to be suffering from female sexual dysfunction.

\section{Statistics}

Data were presented as mean \pm standard deviation (SD) and percentages. Predicted probability for female sexual dysfunction was computed using a multivariate logistic regression model. Area under receiver operating characteristic curve was applied to compare the accuracy of the model. All statistical analyses were performed using SPSS ver. 16.0 software (SPSS Inc., Chicago, IL, USA).

\section{RESULTS}

\section{General Characteristics of the Study Subjects}

A total of 444 women participated in the present study, excluding women with physical and psychosocial problems, medical illnesses and alcohol addiction, and those who consumed drugs that affect sexual function. Overall, 107 (24.1\%) of all participants reported normal sexual function, whereas 337 (75.9\%) suffered from female sexual dysfunction.

\section{Risk for Female Sexual Dysfunction}

The mean \pm SD ages of subjects in the normal sexual function and sexual dysfunction groups were $32.93 \pm 8.66$ and $28.85 \pm 6.42$ years, respectively. A significant difference in the mean age of subjects was detected between the normal sexual function and female sexual dysfunction groups ( $\mathrm{r}=-0.241, \mathrm{P}<0.001)$.

Table 1. Association between female sexual function and other variables using univariate logistic regression analysis

\begin{tabular}{|c|c|c|c|c|}
\hline \multirow{2}{*}{ Characteristic } & \multicolumn{4}{|c|}{ Sexual function } \\
\hline & Normal & Abnormal & Odds ratio (95\% confidence interval) & P-value \\
\hline Total no. & $107(24.1)$ & $337(75.9)$ & & \\
\hline Age (y) & $32.93 \pm 8.66$ & $28.85 \pm 6.42$ & $0.93(0.90-0.96)$ & 0.001 \\
\hline Husband age (y) & $39.20 \pm 4.15$ & $38.97 \pm 5$ & $0.84(0.70-0.98)$ & 0.061 \\
\hline Age of marriage (y) & $22.47 \pm 7.87$ & $22.06 \pm 4.78$ & $0.99(0.951-1.03)$ & 0.527 \\
\hline Age of menarche (y) & $12.76 \pm 1.3$ & 13. $33 \pm 1.4$ & $1.34(1.14-1.57)$ & 0.001 \\
\hline Gravidity & & & & 0.001 \\
\hline Nulligravida & $20(48.8)$ & 21 (51.2) & 1.0 (reference) & \\
\hline Primigravida & $39(29.1)$ & 95 (70.9) & $2.32(1.33-4.75)$ & \\
\hline Multigravid & $48(17.8)$ & $221(82.8)$ & $4.38(2.2-8.72)$ & \\
\hline Parity & & & & 0.003 \\
\hline Nulliparous & $20(43.5)$ & $26(56.5)$ & 1.0 (reference) & \\
\hline Primiparous & $39(25.2)$ & $116(74.8)$ & $2.29(1.15-4.57)$ & \\
\hline Multiparous & 48 (19.8) & $195(80.2)$ & $3.12(1.61-6.04)$ & \\
\hline Level of education & & & & 0.001 \\
\hline College & $47(19.0)$ & 201 (81.0) & 1.0 (reference) & \\
\hline High school & $25(20.0)$ & $100(80.0)$ & $0.93(0.54-1.61)$ & \\
\hline Primary school & $9(25.7)$ & $26(74.3)$ & $0.676(0.3-1.54)$ & \\
\hline Illiterate & 26 (72.2) & $10(27.8)$ & $0.94(0.54-1.6)$ & \\
\hline Husband's education* & & & & 0.060 \\
\hline College & $44(19.4)$ & $183(80.6)$ & 1.0 (reference) & \\
\hline High school & $51(27.7)$ & $133(72.3)$ & $0.63(0.39-0.99)$ & \\
\hline Primary school & $5(50.0)$ & $5(50.0)$ & $0.24(0.07-0.87)$ & \\
\hline Illiterate & $3(27.3)$ & $8(72.7)$ & $0.64(0.16-2.52)$ & \\
\hline Occupation* & & & & 0.492 \\
\hline Official & $50(27.2)$ & $134(72.8)$ & 1.0 (reference) & \\
\hline Home worker & $57(23.6)$ & $185(76.4)$ & $1.21(0.78-1.88)$ & \\
\hline Husband's occupation* & & & & 0.818 \\
\hline Official & $100(24.1)$ & $315(75.9)$ & 1.0 (reference) & \\
\hline Workless & $3(21.4)$ & $11(78.6)$ & $0.86(0.23-3.14)$ & \\
\hline
\end{tabular}

Values are presented as number (\%) or mean \pm standard deviation.

*Variables such as husband's education, occupation, and husband's occupation were calculated following the exclusion of missing values. 
Table 2. Association between female sexual function and other variables using multivariate logistic regression analysis

\begin{tabular}{ccccccc}
\hline Characteristic & $\mathrm{B}^{*}$ & Standard error & Wald & Degree of freedom & P-value & Odds ratio (95\% confidence interval) \\
\hline Gravid & 0.463 & 0.105 & 19.499 & 1 & 0.001 & $1.59(1.3-1.95)$ \\
Education & 0.537 & 0.119 & 20.175 & 1 & 0.001 & $1.71(1.35-2.16)$ \\
Menarche & 0.243 & 0.088 & 7.071 & 1 & 0.008 & $1.26(1.06-1.5)$ \\
Constant & -4.733 & 1.182 & 14.605 & 1 & 0.001 & 0.012 \\
\hline
\end{tabular}

*This is the coefficient for variables.

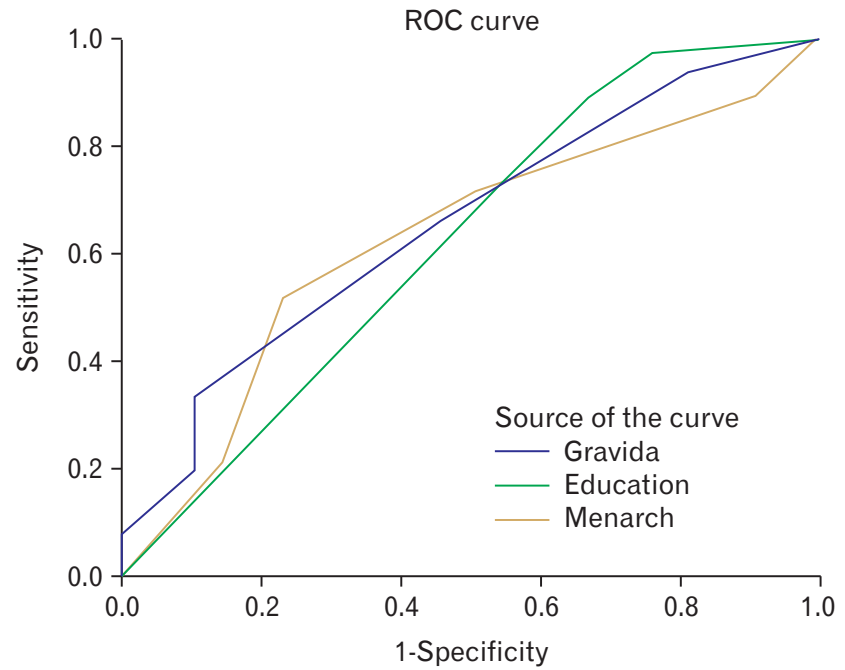

Figure 2. Receiver operating characteristic (ROC) of predicted probabilities, as determined by multivariate logistic regression.

Univariate logistic regression analysis indicated a significant association between female sexual dysfunction and age, menarche age (odds ratio [OR], 1.34; 95\% confidence interval, 1.14 to 1.57 ), gravidity (OR, 4.38; multigravid vs. nulligravida), parity ( $\mathrm{OR}, 3.14$; multiparous vs. nulliparous) and education level (OR, 3.15; illiterate vs. college). No significant association was detected between female sexual dysfunction and the husband's age and family monthly income. Associations between female sexual function and the other variables assessed by univariate logistic regression analysis are presented in Table 1.

Multivariate logistic regression analysis demonstrated that menarche age (OR, 1.26), education level (OR, 1.71; illiterate vs. college), and gravidity (OR, 1.59; multigravid vs. nulligravida) were considered as independent predictive variables for female sexual dysfunction (Table 2). A multivariate logistic regression model for the probability of female sexual dysfunction and the other covariates was estimated as $\operatorname{Ln}(\mathrm{p} / 1-\mathrm{p})=-4.733+0.243$ menarche age +0.537 education level +0.463 gravidity.

The coefficients of the logistic regression model indicated that education level (OR, 1.71; illiterate vs. college) was the variable that was most suitable for the prediction of female sexual dysfunction. To calculate the overall percentage of correct classifications of the model, the predicted values were compared to the observed values. The overall percentage of correct classification of the model was $77.9 \%$. Therefore, when data on the menarche age, gravidity, and education level of the woman are obtained, the ability of the model to predict the actual sexual dysfunction category of the cases is $77.9 \%$. Area under the receiver operating characteristic curve criterion was used to calculate the sensitivity and specificity of the model (Figure 2). The area under the curve represents the probability that the model predicted for a randomly chosen positive case will exceed the result for a randomly chosen negative case. Asymptotic significance was $<0.05$, which indicated that the model is a good method for the prediction of female sexual dysfunction.

\section{DISCUSSION}

Female sexual dysfunction is one of the most common sexual disorders worldwide. Sexual dysfunction may lead to various detrimental consequences, including divorce, violence and, ultimately, depression. ${ }^{10,22)}$ Therefore, the present study was conducted to determine the predictive factors for female sexual dysfunction.

Analysis of the data demonstrated that $75.9 \%$ of the study population experienced female sexual dysfunction in one or more dimensions. Another Iranian study has previously reported the prevalence of female sexual dysfunction as $68.4 \%$ of their study population. ${ }^{23)}$ Cayan et al. ${ }^{24)}$ evaluated the prevalence of sexual dysfunction among 179 Turkish women aged 18-66 years, and reported the prevalence as $47 \%$. Furthermore, a population-based study demonstrated that female sexual dysfunction affected $43 \%$ of married women in rural China. ${ }^{24)}$ The results of the present study indicated a significant association between female sexual dysfunction and gravidity using univariate logistic regression analysis: multi-gravid women had a 4.38 times higher risk of female sexual dysfunction compared to nulli-gravida women. So far, studies have examined the impact of various factors such as physical condition $^{25)}$ and fertility of female sexual function. ${ }^{10)}$

Pregnancy is a period of particularly distinct physical, hormonal, and psychological changes. Previous studies have investigated the effect of pregnancy on women's sexuality and sexual relationships. ${ }^{26,27)}$

Univariate logistic regression analysis demonstrated a positive association between parity and female sexual dysfunction. In another study, multi-parity was indicated as an important risk factor of sexual dysfunction in Turkish women. ${ }^{24)}$

In the present study, multivariate logistic regression analysis demonstrated a significant difference in gravidity between women with normal and abnormal sexual function, and the risk of female sexual dysfunction was 1.96 times higher in multigravid women, as compared 
with nulligravid women. However, this result was not consistent with the findings of a previous Egyptian study, which demonstrated that there was not a significant association between female sexual dysfunction and gravidity. ${ }^{26)}$

It is believed that individuals who complete a higher level of academic education experience increased sexual satisfaction. The present study reported that education level was an independent predictive variable for female sexual dysfunction. It is likely that the causes of sexual dysfunction in illiterate women are associated with increased daily physical activity and stressful socio-economical conditions in this group. However, an Iranian study, reported that the prevalence of female sexual dysfunction is higher in under diploma and doctorate education groups in comparison to other groups. ${ }^{28)}$

Despite the major impact of female sexual function on marital satisfaction and quality of life, approximately $75 \%$ of Iranian married women suffer from sexual dysfunction. The roles of religious and socio-cultural factors in sexual function are well-documented. The lack of attention given to Iranian women's sexual pleasure is an important factor for the high prevalence of sexual dysfunction among women. Among Iranian couples, sex is predominantly initiated on the basis of the man's desire ${ }^{29)}$ Furthermore, there is a lack of formal training concerning sexual function and its influencing factors in Iran; therefore, most Iranians are unaware of the impact of sexual function and its influencing factors. This often results in this required information being provided from wrong and invalid sources. However, in the majority of cases these women are unaware of their own sexual dysfunction. ${ }^{30}$

In conclusion, the findings of the present study indicated that there are several risk factors for female sexual dysfunction. Gravidity, menarche age and education level were demonstrated to be independent predication variables for female sexual dysfunction. Recognition of these predictive factors may improve the diagnosis of female sexual dysfunction.

\section{CONFLICT OF INTEREST}

No potential conflict of interest relevant to this article was reported.

\section{ACKNOWLEDGMENTS}

The present study was approved by the Ethics Committee of the Ilam University of Medical Sciences. We thank the participants, coordinators, and data collectors who assisted in this study.

\section{REFERENCES}

1. Direkvand-Moghadam A, Khosravi A, Sayehmiri K. Predictive factors for preeclampsia in pregnant women: a Receiver Operation Character approach. Arch Med Sci 2013;9:684-9.

2. Direkvand-Moghadam A, Sayehmiri K, Delpisheh A, Kaikhavandi S. Epidemiology of Premenstrual Syndrome (PMS): a systematic review and meta-analysis study. J Clin Diagn Res 2014;8:106-9.
3. Zhang H, Fan S, Yip PS. Sexual dysfunction among reproductive-aged Chinese married women in Hong Kong: prevalence, risk factors, and associated consequences. J Sex Med 2015;12:738-45.

4. Eden KJ, Wylie KR. Quality of sexual life and menopause. Womens Health (Lond) 2009;5:385-96.

5. Cavalcanti IF, Farias PD, Ithamar L, Silva VM, Lemos A. Sexual function and factors associated with sexual dysfunction in climacteric women. Rev Bras Ginecol Obstet 2014;36:497-502.

6. Wallwiener CW, Wallwiener LM, Seeger H, Muck AO, Bitzer J, Wallwiener M. Prevalence of sexual dysfunction and impact of contraception in female German medical students. J Sex Med 2010;7:2139-48.

7. Brezsnyak M, Whisman MA. Sexual desire and relationship functioning: the effects of marital satisfaction and power. J Sex Marital Ther 2004;30:199-217.

8. Litzinger S, Gordon KC. Exploring relationships among communication, sexual satisfaction, and marital satisfaction. J Sex Marital Ther 2005;31:409-24.

9. Kennedy CM, Turcea AM, Bradley CS. Prevalence of vulvar and vaginal symptoms during pregnancy and the puerperium. Int J Gynaecol Obstet 2009;105:236-9.

10. Ashraf DM, Ali D, Azadeh DM. Effect of infertility on sexual function: a cross-sectional study. J Clin Diagn Res 2015;9:QC01-3.

11. Kennedy SH, Dickens SE, Eisfeld BS, Bagby RM. Sexual dysfunction before antidepressant therapy in major depression. J Affect Disord 1999;56:201-8.

12. Brtnicka $H$, Weiss $P$, Zverina J. Human sexuality during pregnancy and the postpartum period. Bratisl Lek Listy 2009;110:427-31.

13. Kingsberg SA. The impact of aging on sexual function in women and their partners. Arch Sex Behav 2002;31:431-7.

14. Drosdzol A, Skrzypulec V. Evaluation of marital and sexual interactions of Polish infertile couples. J Sex Med 2009;6:3335-46.

15. Direkvand-Moghadam A, Delpisheh A, Direkvand-Moghadam A, Karzani P, Saraee P, Safaripour Z, et al. Predictive factors for infertility of women: an univariate and multivariate logistic regression analysis. Int J Epidemiol Res 2015;2:4-11.

16. Shifren JL, Monz BU, Russo PA, Segreti A, Johannes CB. Sexual problems and distress in United States women: prevalence and correlates. Obstet Gynecol 2008;112:970-8.

17. Anis TH, Gheit SA, Saied HS, Al kherbash SA. Arabic translation of Female Sexual Function Index and validation in an Egyptian population. J Sex Med 2011;8:3370-8.

18. Nowosielski K, Wrobel B, Sioma-Markowska U, Poreba R. Development and validation of the Polish version of the Female Sexual Function Index in the Polish population of females. J Sex Med 2013;10:38695.

19. Lee Y, Lim MC, Joo J, Park K, Lee S, Seo S, et al. Development and validation of the Korean version of the Female Sexual Function Index- 6 (FSFI-6K). Yonsei Med J 2014;55:1442-6.

20. Ghassamia M, Asghari A, Shaeiri MR, Safarinejad MR. Validation of psychometric properties of the Persian version of the Female Sexual Function Index. Urol J 2013;10:878-85.

21. Fakhri A, Pakpour AH, Burri A, Morshedi H, Zeidi IM. The Female Sexual Function Index: translation and validation of an Iranian version. J Sex Med 2012;9:514-23.

22. Lau JT, Cheng Y, Wang Q, Yang X. Prevalence and correlates of sexual 
dysfunction among young adult married women in rural China: a population-based study. Int J Impot Res 2006;18:89-97.

23. Abdollahi M, Toghae M, Raisi F, Saffari E. The prevalence of female sexual dysfunction among migraine patients. Iran J Neurol 2015;14:811.

24. Cayan S, Akbay E, Bozlu M, Canpolat B, Acar D, Ulusoy E. The prevalence of female sexual dysfunction and potential risk factors that may impair sexual function in Turkish women. Urol Int 2004;72:52-7.

25. Mozafari M, Khajavikhan J, Jaafarpour M, Khani A, Direkvand-Moghadam A, Najafi F. Association of body weight and female sexual dysfunction: a case control study. Iran Red Crescent Med J 2015;17:e24685.

26. Hanafy S, Srour NE, Mostafa T. Female sexual dysfunction across the three pregnancy trimesters: an Egyptian study. Sex Health 2014;11:
240-3.

27. Ahmed MR, Madny EH, Sayed Ahmed WA. Prevalence of female sexual dysfunction during pregnancy among Egyptian women. J Obstet Gynaecol Res 2014;40:1023-9.

28. Abdoly M, Pourmousavi L. The relationship between sexual satisfaction and education levels in women. Int J Womens Health Reprod Sci 2013;1:39-44.

29. Rahimi-Movaghar A, Yousefi-Nooraie R, Noorbala AA, Vahid-Vahdat S, Bayay Z, Arbabi M, et al. Systematic review of prevalence of sexual disorders in Iran. Iran J Psychiatry 2007;2:151-6.

30. Ramezani MA, Ahmadi K, Ghaemmaghami A, Marzabadi EA, Pardakhti F. Epidemiology of sexual dysfunction in Iran: a systematic review and meta-analysis. Int J Prev Med 2015;6:43. 